\title{
BIOLOGY AND SYSTEMATICS OF THE \\ BEE GENUS CRAWFORDAPIS \\ (COLLETIDAE, DIPHAGLOSSINAE)
}

\section{By Gard W. Otis 1 , Ronald J. McGinley ${ }^{2}$, Lyn Garling 3 , AND LUIS MALARET ${ }^{3}$}

Crawfordapis luctuosa (Smith) is a robust, dusky-haired bee, presently known from only a few localities in Mexico and Central America. Individuals can be as long as $24 \mathrm{~mm}$ and superficially resemble the more familiar diphaglossine bees of the genera Ptiloglossa and Caupolicana to which they are related. All three genera are placed in the Caupolicanini which is characterized by the complete preepisternal groove and very elongate first flagellar segment. While Crawfordapis is currently considered to be monotypic, Michener (1966) raised the possibility that the material from the more northern localities (Mexico and Guatemala) may represent a distinct species. Much more material from different localities is needed before that problem can be considered.

The purpose of this paper is to present biological observations made on Crawfordapis by three of us in Costa Rica (L.G., L.M., G.O.). In addition, the larva of Crawfordapis is described and the systematic interrelationships of diphaglossine genera are reviewed (R.M.).

\section{BIOLOGY}

\section{Description of the Site}

Two nesting aggregations of Crawfordapis luctuosa were observed approximately $5 \mathrm{~km}$ east of Monteverde, Province of Puntarenas, Costa Rica $\left(10^{\circ} 18^{\prime} \mathrm{N}, 84^{\circ} 47^{\prime} \mathrm{W}\right)$ on trails at $1540 \mathrm{~m}$ elevation. The surrounding vegetation is best described as elfin forest, with some characteristic plant species being Lycopsidium cernuum, Senecio megaphyllus, Clibadium sp., Gunnera sp. and Myrica phanerodouta

\footnotetext{
'Environmental Biology Dept., University of Guelph, ON N1G 2W1, Canada. ${ }^{2}$ Museum of Comparative Zoology, Harvard University, Cambridge, MA 02138.

Present address: Dept. of Entomology, N.H.B. 105, Smithsonian Inst., Washington, D.C. 20560.

${ }^{3}$ Dept. of Zoology, University of Florida, Gainesville, FL 32611

Manuscript received by the editor July 7, 1982
} 
(details in Lawton and Dryer, 1980). Frequent rains deposit approximately $3000 \mathrm{~mm}$ of precipitation annually on this area. Heavy mists augment this precipitation. Mean annual temperature is about $16^{\circ} \mathrm{C}$ $\left(\max =27^{\circ} \mathrm{C}, \min =10^{\circ} \mathrm{C}\right)$ and during prolonged rainstorms, the temperature can remain at $15-16^{\circ} \mathrm{C}$ for $3-4$ days. The wind generally blows 15 to $20 \mathrm{~km} / \mathrm{hr}$, but ranges from nearly calm to winds in excess of $100 \mathrm{~km} / \mathrm{hr}$ during rainstorms (R. Lawton, pers. comm.).

Nesting aggregation No. 1 was directly on the Continental Divide, on a narrow ridge known as "La Ventana". The aggregation was first noticed in August 1975 and was still active but reduced in size to only 5 nests in February 1981. W. Guindon (pers. comm.) indicated the site was active as early as 1966 . Bees apparently maintained nests in this area throughout the year (R. Lawton, pers. comm.). Nests were built in the lee of a slope which partially protected them from mist and rain (Fig. 1). In July 1977, there were 97 nests with tumuli in the approximately $18 \mathrm{~m}$ aggregation. The majority of the nests were within an elliptical area of about $8 \mathrm{~m}$. Of the nests 29 were completely exposed in the trail, 50 were on nearly level ground and partially obscured by grasses and other herbs, and 18 were on the face of the sheltering embankment.

Nesting aggregation No. 2, located at the head of the valley on the road to Penas Bancas, was exposed to high winds and unprotected from rain (Fig. 2). In February 1978, the aggregation consisted of not more than 100-150 nests, but had enlarged to at least four hundred active nests by August 1978. Nests were found both on the edge of the road and down the adjacent steep, bare slope. By the last visit to the site in February 1981, the number of active nests had declined to 230 . The adjacent slope had become covered with dense vegetation and lacked nests.

\section{Description of the Nest}

Entrances to active nests had tumuli approximately $7.5 \mathrm{~cm}$ in diameter and 4-7 cm in height (Fig. 3). The frequent rains obliterated tumuli of all nests except those in which bees were actively digging. Nest entrances consistently measured $1.0 \mathrm{~cm}$ in diameter. In each of three nests excavated in horizontal ground, the tunnel began nearly vertically for 7-14 cm and then continued downward at an angle of approximately $75^{\circ}$. In the diagrammed nest (Fig. 4) 

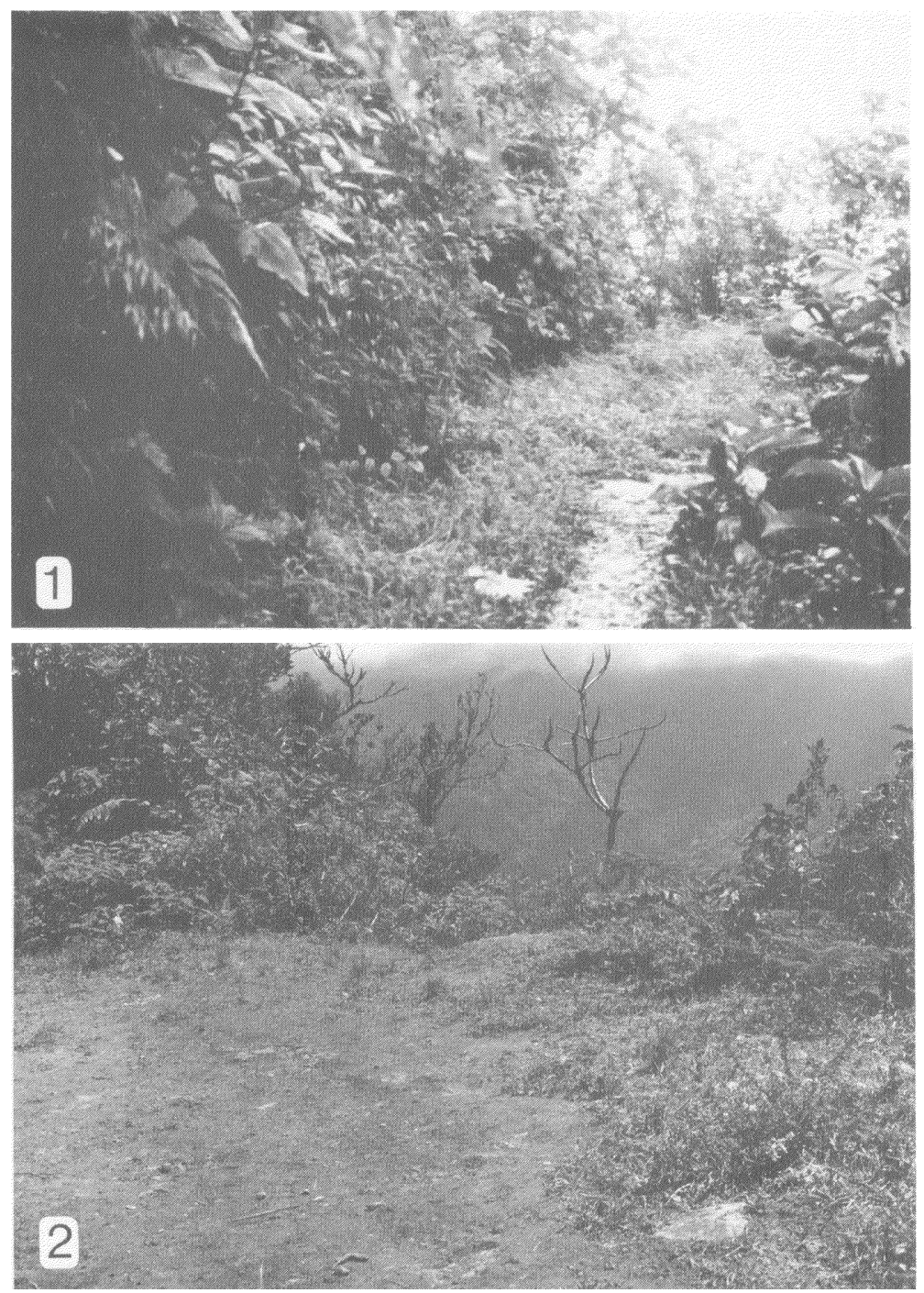

Figures 1-2. Crawfordapis luctuosa nesting sites. Fig. 1. Nest aggregation No. 1. Most nests were on level ground, either exposed or partially obscured by grasses. A smaller number of nests were in the nearly vertical embankment which sheltered the site from wind and mist. Fig. 2. Nest aggregation No. 2. 


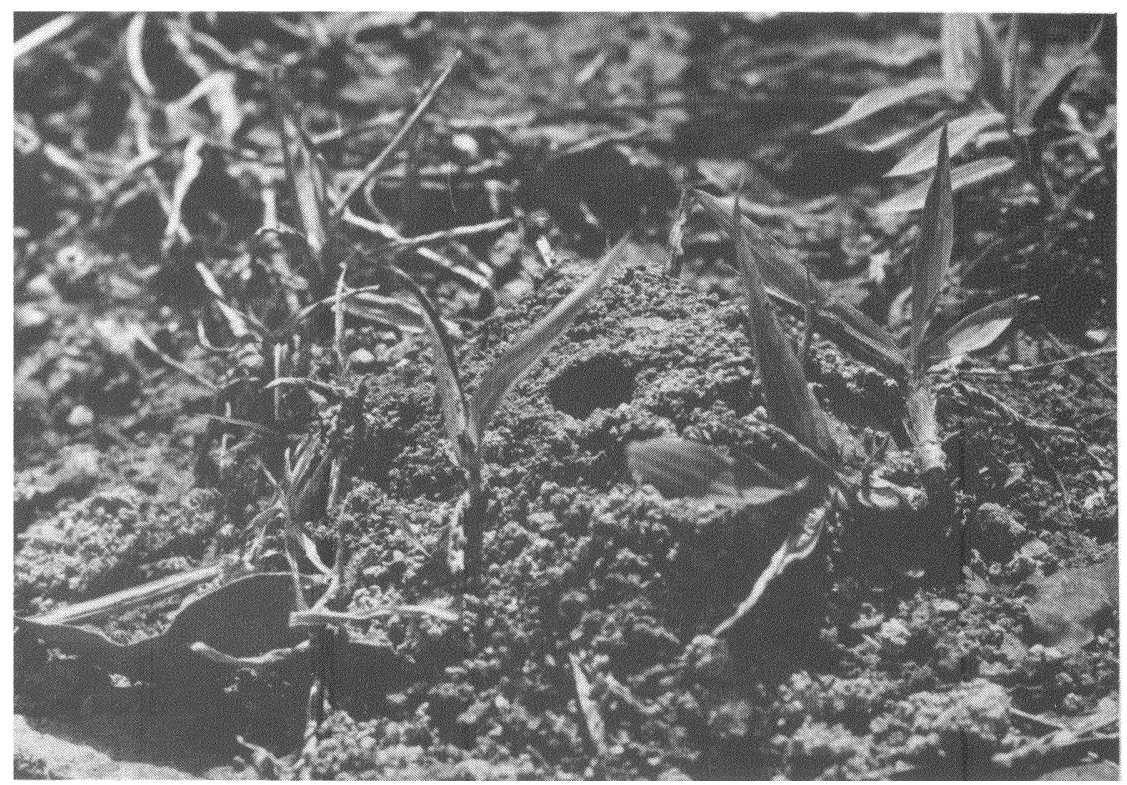

Figure 3. Nest tumulus. Nests in which bees were actively digging were readily discerned by the presence of a dirt mound around the nest entrance.

the tunnel changed directions again at at a depth of $24 \mathrm{~cm}$, continued downward at a $75^{\circ}$ angle another $8 \mathrm{~cm}$, and diverged into two tunnels. One of these angled toward the embankment at an angle of $50^{\circ}$ from vertical for another $12 \mathrm{~cm}$, then at a depth of $41 \mathrm{~cm}$ continued slightly below horizontal for another $18 \mathrm{~cm}$. A single, terminal cell was found at the end of that tunnel. The other tunnel continued downward another $16 \mathrm{~cm}$ from the branching point before becoming nearly horizontal at a depth of $47 \mathrm{~cm}$. This tunnel could not be followed because the soil was too soft.

Two additional nests were excavated on the nearly vertical embankment at aggregation No. 1. These nests differed from those in level ground in having very short $(3-5 \mathrm{~cm})$ vertical portions of the tunnel before becoming nearly horizontal. Nest B (Fig. 5) had a single horizontal tunnel that extended $22 \mathrm{~cm}$ into the embankment. Along the slight downward slope of this main tunnel were 6 nearly horizontal lateral tunnels $4-8 \mathrm{~cm}$ long. The two closest to the exterior contained pupae and the tunnels had been filled with soil. The next three contained larvae, and the distal cell was empty. Nest $C$ 


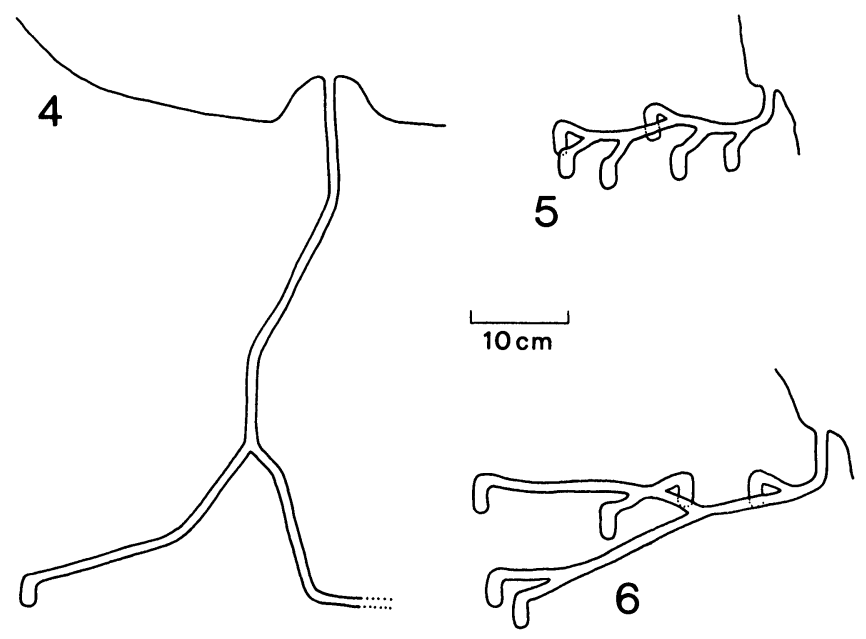

Figures 4-6. Diagrammatic representation of three $C$. luctuosa nests. Fig. 4. Nest at base of the embankment. Figs. 5-6. Nests excavated in the embankment.

(Fig. 6) had one cell (contents unrecorded) only $4 \mathrm{~cm}$ from the vertical entrance tunnel. Another $8 \mathrm{~cm}$ further down, the main tunnel diverged into two. One tunnel continued to slope downward and contained two terminal cells with pupae. The other tunnel sloped slightly upward and had two lateral cells with larvae and an empty terminal cell which was $34 \mathrm{~cm}$ from the face of the embankment.

Each completed cell was lined with a shiny, cellophane-like membrane which is characteristic of Colletidae. It was not possible to lift the cell and contents out of the soil as described for Ptiloglossa guinnae Roberts (Roberts, 1971). Cell contents were soupy; fermentation odors were not recorded. Cocoons were tough, nearly transparent membranes $17 \mathrm{~mm}$ in diameter by $35 \mathrm{~mm}$ in length.

\section{General Activity Pattern}

Females of Crawfordapis luctuosa were active aboveground primarily between the hours of 0930 and $1400 \mathrm{hr}$, with few bees leaving the nests after $1300 \mathrm{hr}$ on observation days February 19 and 20, 1978 (Fig. 7). A similar activity pattern was recorded on July 16, 1977. This sharply contrasts with the crepuscular activity pattern of Ptiloglossa guinnae which occurs in similar habitats (Roberts, 1971). In some instances, bees were seen returning to the nests in the morning before any bees left the nesting aggregation. It is possible 
that these bees had spent the night away from their nests as occurs with Bombus species at high elevations (O. R. Tayor, pers. comm.). Before leaving the nest for the first time in the morning, females often remained just below the nest entrance for a few moments and then upon exiting, hovered nearby for a short time before flying off. Temperatures within the nest entrance remained at $12^{\circ} \mathrm{C}$ throughout the day on February 20 when ambient temperature was between $10-11^{\circ} \mathrm{C}$.

Males remained outside the nests at all times. During the activity period of the females, the males flew over the nesting aggregation and nearby at heights of 1-3 $\mathrm{m}$. They rapidly approached any flying object, including female $C$. luctuosa, swallows, a hummingbird, a ctenuchid moth and a dragonfly. Males often seized females returning to the nests but it was not ascertained whether copulations occurred.

\section{Nest Visitation Behavior}

On February 19 and 20,1978, 46 nests within a $2.16 \mathrm{~m}$ subarea of aggregation No. 2 were mapped and numbered. Sixteen female bees were captured while leaving nests. Each bee and her corresponding nest of origin were given an identifying color combination. The bees were marked by paint spots on the thorax, while their nests of origin were indicated by a wooden chip about $1 \mathrm{~cm}$ in length placed near the entrance. All observed departures from and arrivals to mapped nests were recorded by noting time, markings (or lack thereof) of bees and nest number or color. A nest "visit" was defined as the disappearance of the bee beneath the ground surface for any length of time.

Of the 46 nests mapped, $40(80 \%)$ were entered at least once by a bee. The number of observed visits per nest made by marked or unmarked bees to the 16 color-coded nests ranged from $0-15$ over the two days (Table 1).

Of the 16 marked bees, four were not observed again. The remaining 12 marked bees visited nests a total of 78 times. Four of the marked bees (BG, GO, YBY, OB) concentrated their visits on a single nest, while others entered up to 12 different nests over the two days (Table 2).

The duration of visits of both marked and unmarked bees varied widely from less than 1 minute to a maximum of 151 minutes. The 


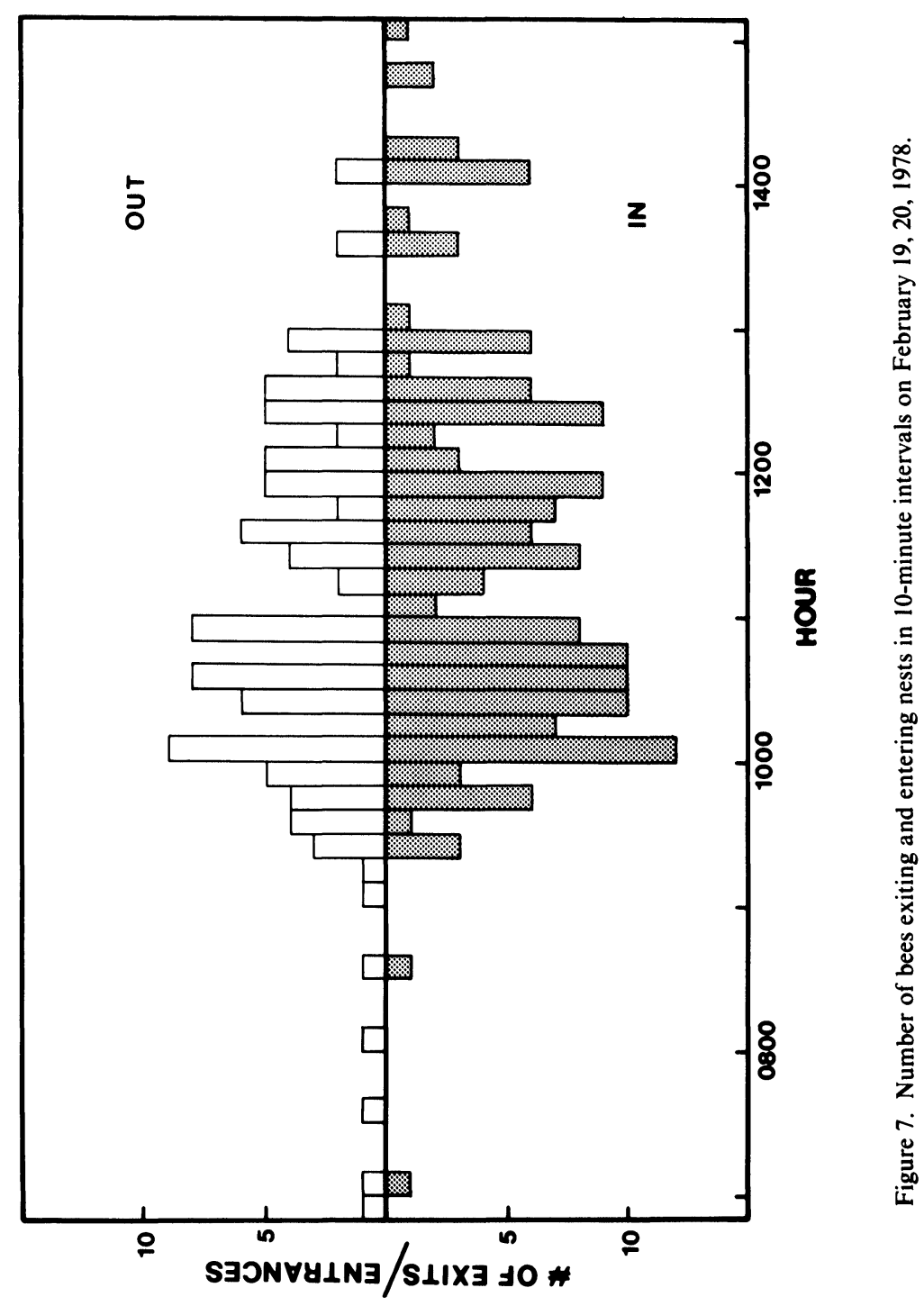


Table 1. Number of visits by all bees to color-coded nests

\begin{tabular}{|l|llllllllllllllllll|}
\cline { 2 - 4 } \multicolumn{1}{c|}{} & \multicolumn{11}{|c|}{ Nest Color-Code } \\
\cline { 2 - 3 } & YB & OY & YO & GO & BG & YBY & Y & OBO & O OB & BY & YG & B & GB & OG & BOY \\
\hline $\begin{array}{c}\text { No. of } \\
\text { visits }\end{array}$ & 8 & 15 & 4 & 7 & 11 & 8 & 0 & 4 & 2 & 8 & 2 & 0 & 7 & 4 & 3 & 0 \\
\hline
\end{tabular}

Table 2. Number of visits made by marked bees to particular nests.

\begin{tabular}{|c|c|c|c|c|c|c|c|c|c|c|c|c|c|}
\hline \multirow{2}{*}{$\begin{array}{c}\text { Marked } \\
\text { bee }\end{array}$} & \multicolumn{13}{|c|}{ Nest Categories } \\
\hline & $1^{\circ}$ & $2^{\circ}$ & $3^{\circ}$ & $4^{\circ}$ & $5^{\circ}$ & $6^{\circ}$ & $7^{\circ}$ & $8^{\circ}$ & $9^{\circ}$ & $10^{\circ}$ & $11^{\circ}$ & $12^{\circ}$ & Total visits \\
\hline YB & 3 & 2 & 2 & 2 & 2 & 2 & $1^{*}$ & 1 & 1 & 1 & 1 & 1 & 19 \\
\hline OY & $6^{*}$ & 4 & 2 & 1 & 1 & 1 & 1 & 1 & 1 & 1 & & & 19 \\
\hline YO & $2^{*}$ & 2 & 2 & 1 & 1 & 1 & 1 & 1 & & & & & 11 \\
\hline GO & 5 & 1 & 1 & 1 & 1 & & & & & & & & 8 \\
\hline BG & $5^{*}$ & & & & & & & & & & & & 5 \\
\hline $\mathbf{Y}$ & 1 & 1 & 1 & & & & & & & & & & 3 \\
\hline YBY & $3^{*}$ & & & & & & & & & & & & 3 \\
\hline OB & $3^{*}$ & & & & & & & & & & & & 3 \\
\hline ОВО & 2 & & & & & & & & & & & & 2 \\
\hline & 1 & 1 & & & & & & & & & & & 2 \\
\hline $\mathrm{BY}^{*}, \mathrm{YG}$ & Each & visi & 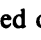 & ne $n$ & st o & ice. & & & & & & & \\
\hline
\end{tabular}

*Asterisked entries indicate that the visits were made to the nest from which the bee was originally captured.

visits of 1 minute or less were likely to have been exploratory rather than "working" visits. Of a total of 69 timed visits, 30 (43\%) were in the "exploratory" category. The average duration of the remaining 39 "working" visits was 18.1 minutes $(\mathrm{S}=26.36$ ) (Fig. 8).

The duration of foraging trips of 4 of the marked bees was noted by timing of their absences from the nest area. Whether or not they returned with pollen was not noted. Absences ranged from 19-42 minutes, the average being 30.4 minutes $(n=11, s=13.79)$. It seemed that bees returned from foraging trips in distinct pulses of several bees at a time. The foodplants are not known.

This preliminary data on the movements of marked bees to different nests generates several hypotheses for further testing.

1) Multiple nest entering is part of searching behavior for a female's own nest. 


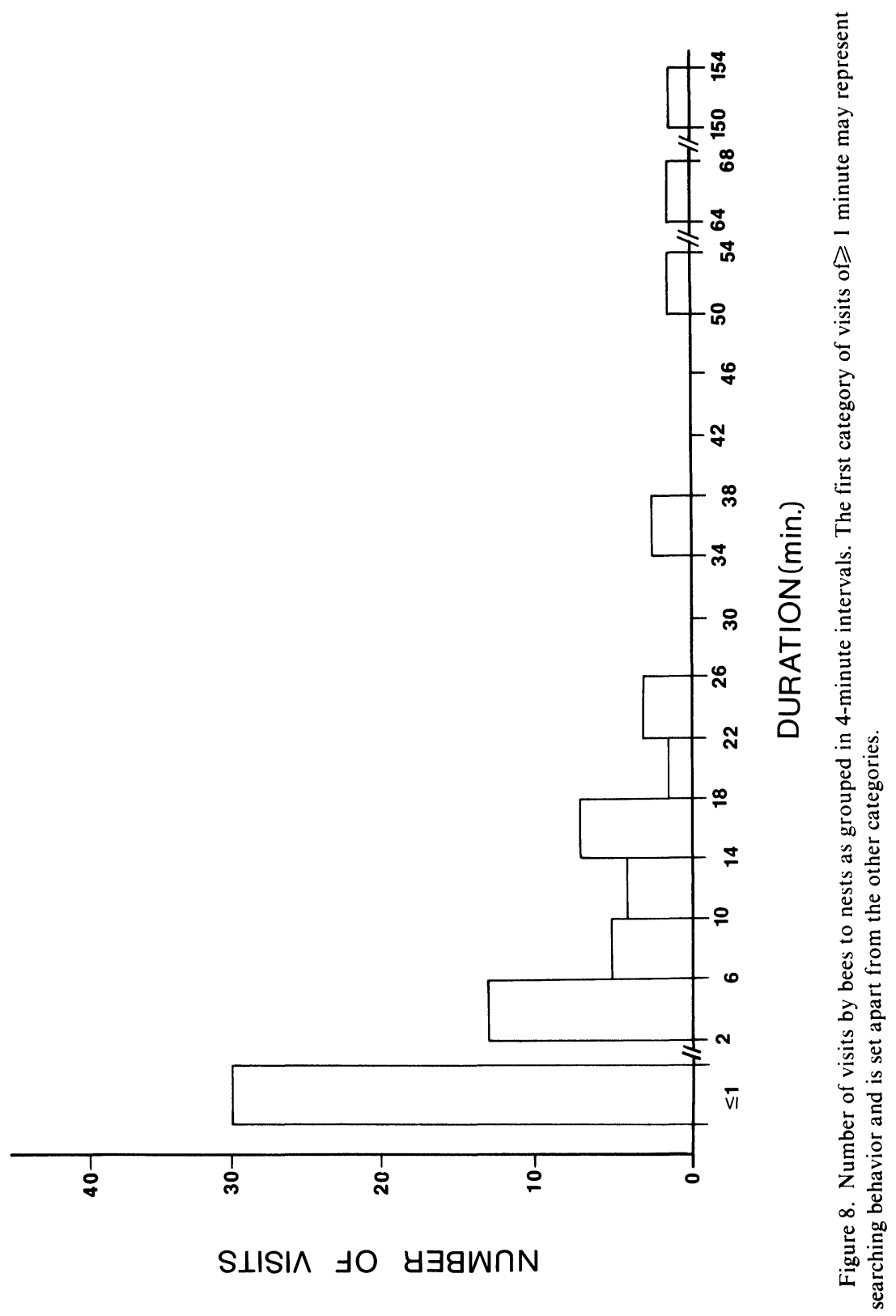


2) Individuals are locating abandoned nests to provision rather than starting completely new ones.

3) Individuals are "stealing" provisions from nests of other individuals.

4) Individuals are usurping nests which other individuals are actively excavating or provisioning.

5) Several individuals are contributing to excavation, provisioning or oviposition within a single nest.

The latter hypothesis is particularly interesting since no species of the family Colletidae is known to be parasocial (Michener, 1974). It is plausible that females not only construct their own nests but also usurp partially constructed or provisioned nests of other females as has been reported in some other Hymenoptera that nest in aggregations (Brockmann and Dawkins, 1979; Brockmann et al., 1979; Eickwort, 1975; Eickwort, 1981; Eickwort et al., 1977). Further studies of Crawfordapis luctuosa are needed to better understand its social behavior and biology.

\section{Systematics}

\section{Description of Larva}

The following description follows the format used for describing other colletid larvae (McGinley, 1981).

HEAD (Figs. 9-13): (2) Labrum nonspiculate; (3) epipharynx and (4) hypopharynx spiculate; (5) maxilla spiculate on inner surface. (7) Head size normal in comparison to body (head not relatively large as in Xeromelissinae); (8) head capsule somewhat elongate, slightly produced in lateral view; (10) frontal swellings above antennae absent; (10a) median frontal swelling above antennae absent (present only in Ptiloglossa). (14) Anterior tentorial pit low in position (high in all other known diphaglossines); (15) posterior tentorial pit at junction of hypostomal ridge and posterior thickening of head capsule; (15a) tentorial development unknown (tentorium of specimen examined was incomplete, probably due to nearness of specimen to pupation). (16) Posterior thickening of head capsule moderately developed (17) straight medially, not curved forward; (19) median longitudinal thickening of head capsule absent; (20) hypostomal ridge well-developed; (25) epistomal ridge complete but thin, (26) arching dorsally to level of antennae. (27) Parietal bands distinct, broad and shallow. (28) Antennal prominence absent; (29) 


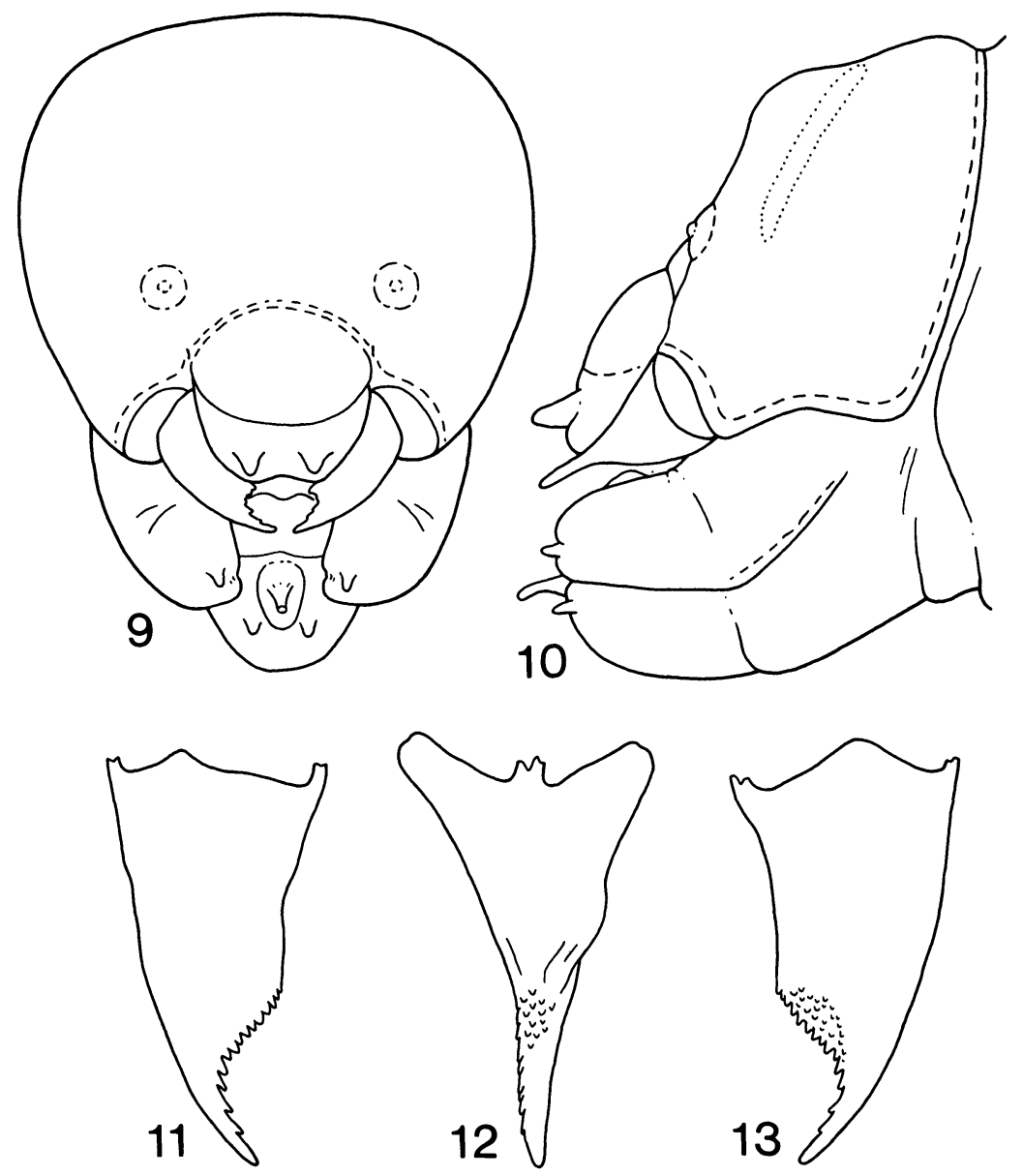

Figures 9-13. Mature larva of Crawfordapis luctuosa. Figs. 9, 10. Head capsule, frontal and lateral view. Figs. 11-13. Right mandible, dorsal, adoral and ventral view.

antennal papilla a moderate-sized convexity, (31) bearing three sensilla. (32) Clypeus moderate in length; (34) labrum not projecting in lateral view; $(35,36,37)$ labral tubercles very well-developed, narrowly rounded and strongly projecting (unlike those of other diphaglossines); (38) labral apex emarginate, (39) without sensillabearing swellings as in other diphaglossines. (41) Mandibles elon- 
gate, (42) moderately slender in dorsal view, (43) broad basally in adoral view; (44) mandibular spiculation absent; (46) outer surface of mandible smooth, distinct tubercle and setae absent; (51) apical portion of mandible, in adoral view, attenuate; (52) cusp moderately well-defined; (53) cuspal projection absent; (54) cuspal region multidentate; $(55,55 a)$ dorsal apical edge with distinct, moderately large teeth; (57) apical concavity weakly developed; $(60,60$ a) ventral apical edge smooth, teeth absent. (61) Labiomaxillary region produced; (62) labium and maxilla distinct, (63) subequal in length. (65) Inner apical surface of maxilla rounded, not produced mesiad; (66) unlike all other known bee larvae except those of Ptiloglossa, maxilla with a longitudinal groove on adoral surface; (67) cardo and stipes sclerotized; $(69,70)$ maxillary palpus moderately elongate and slender, (71) apically positioned on maxillary apex in lateral view; (72) galea absent. (73) Labium divided into prementum and postmentum; (75) palpus elongate and slightly decurved, (76) subequal to maxillary palpus in length. (77) Salivary lips well-developed; $(78,79,80)$ salivary opening narrow, circular, at end of long spoutlike salivary lips, (83) which project from a well-defined platelike structure at apex of labium; (82) apical labial swellings absent. (84) Hypopharynx normal in size, (85) bilobed, (86) exceeded by labium and maxilla; (87) hypopharyngeal groove distinct, sclerotized laterally.

BODY (Fig. 14): (88) Integument spiculate, density of spicules greater on dorsum than on venter; (93) body moderate in length, (94) robust, (95) widest posteriorly in lateral view; (96) intersegmental lines moderately incised; (97) intrasegmental lines indistinct; (98) dorsal tubercles weakly developed, most prominent on abdominal segments 5-7; (103) lateral tubercles absent (present on one specimen from Panama); (104) ventrolateral tubercles absent; (106) abdominal segment 10 moderate in length, (107) rounded, (108) dorsal in attachment to segment 9; (109) venter of segment 10 slightly produced (very weakly so in specimen from Panama), (110) without conspicuous, darkly pigmented spiculation; (111) dorsal surface of segment 10 smooth, without lines or ridges; (113) anus apical. (114) Spiracles large, (115) not on elevations; (117) atrium very broad and shallow, (118) not produced above body surface; (119) atrial wall faintly ridged, (120) with four to five broken rings of spicules; (121) atrial rim absent; (122) peritreme wide; (123) primary tracheal collar absent; (126) subatrium apparently extremely 


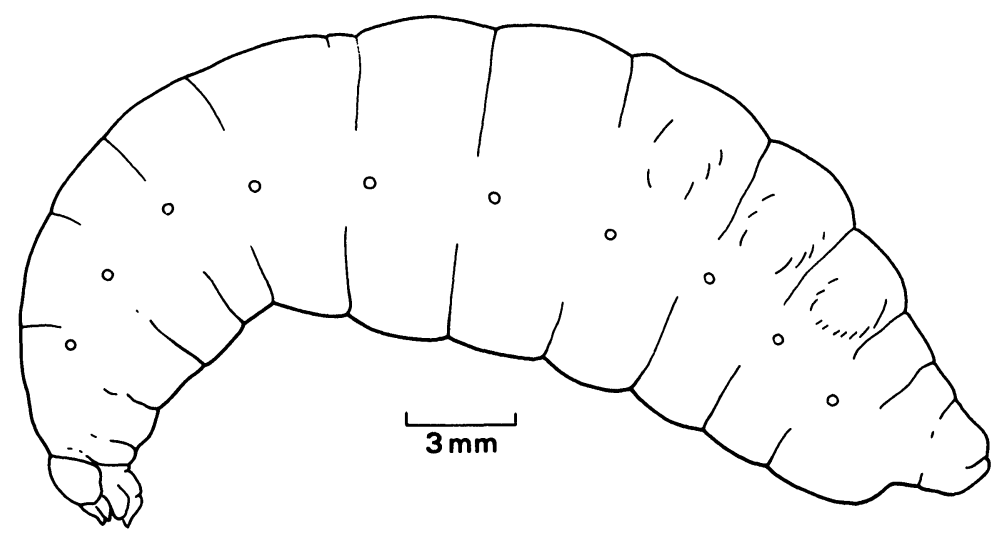

Figure 14. Mature larva of Crawfordapis luctuosa.

short. (The structure of diphaglossine larval spiracles remains poorly understood, especially with regard to the subatrium. The atrium is connected to the trachea by a long, nonringed tube. While this tube is characteristic of diphaglossines, its internal structure and homologies are not known.)

MATERIAL STUDIED: Two postdefecating larvae; $5 \mathrm{~km}$ east Monteverde, Puntarenas Province, Costa Rica; July 16, 1977 (G. W. Otis); specimens in the larval bee collection of the American Museum of Natural History. Two postdefecating larvae; Bouquete, Chiriqui Province, Panama; April 25, 1981 (R. W. Brooks); specimens in the personal collection of R. W. Brooks.

\section{Analysis of Larval Characters}

McGinley (1981) described the mature larvae of 30 colletid species including those of seven diphaglossines. Two cladograms for the diphaglossine genera appeared to be most strongly supported by larval characters. One of the cladograms, for reasons discussed in the above mentioned paper, appeared to be the preferable working hypothesis of diphaglossine phylogeny. This cladogram is presented in Figure 15, with Crawfordapis now included. The polarities of the characters listed in Table 3 were determined by out-group comparison, i.e., consideration of character state distributions in all other bee larvae as well as in nonapoid larvae, especially those of specoid wasps. 


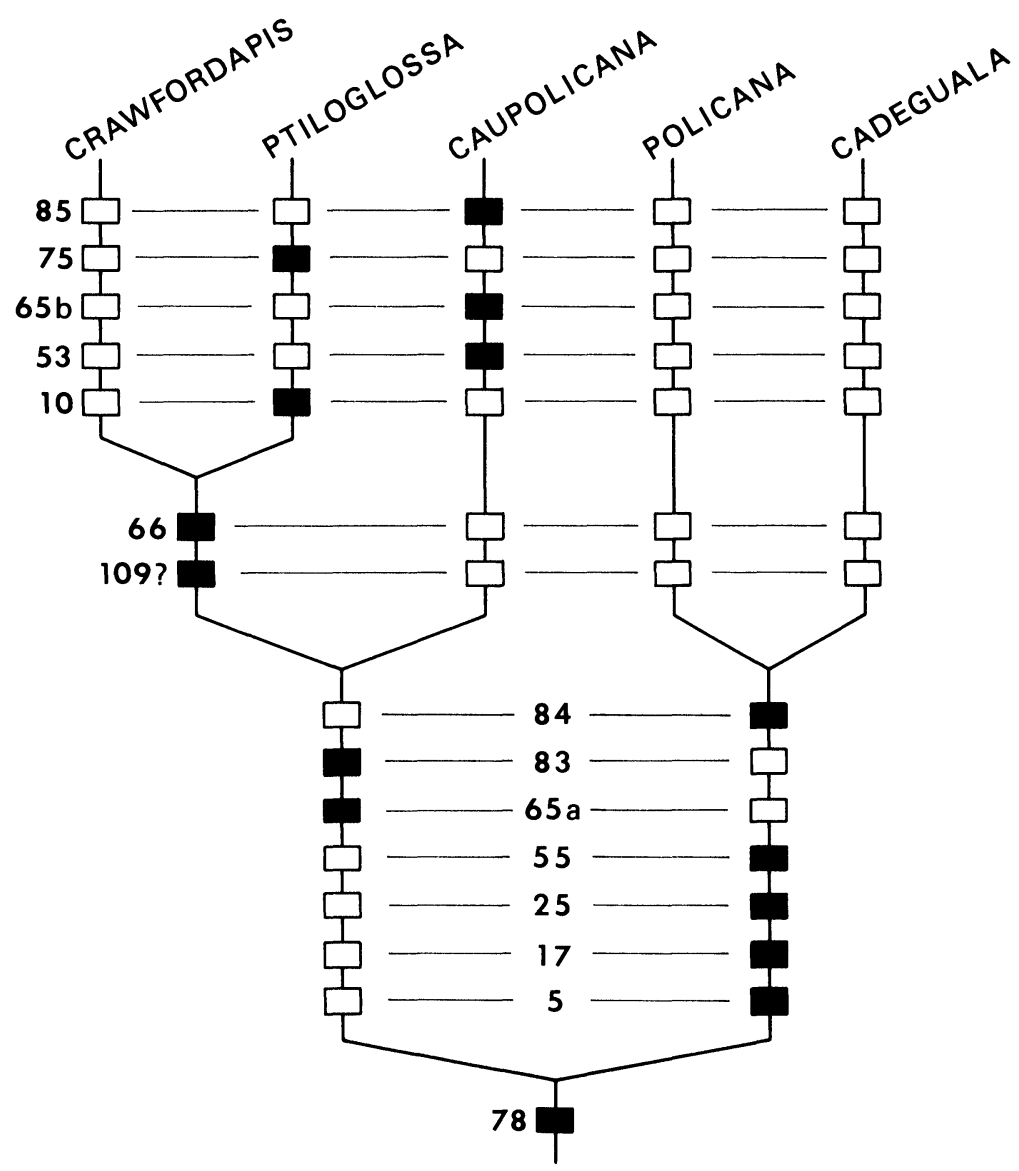

Figure 15. Cladogram of diphaglossine genera based on larval characters. Numbers refer to the characters listed in Table 3. Black rectangles represent presumed apomorphic characters; white rectangles represent plesiomorphic characters. Character 109 appears to be variable in Crawfordapis.

The larval cladogram corroborates the currently recognized diphaglossine classification based on adult characters (Michener, 1966). Recognition of the Caupolicanini (Ptiloglossa, Crawfordapis, Caupolicana) is supported by the presence of the unusual salivary plate (character 83, Fig. 9) and the rounded, nonprojecting inner maxillary surface (character 65 ). 
Table 3. Larval Characters Used in Diphaglossine Cladogram

Plesiomorphic

Apomorphic

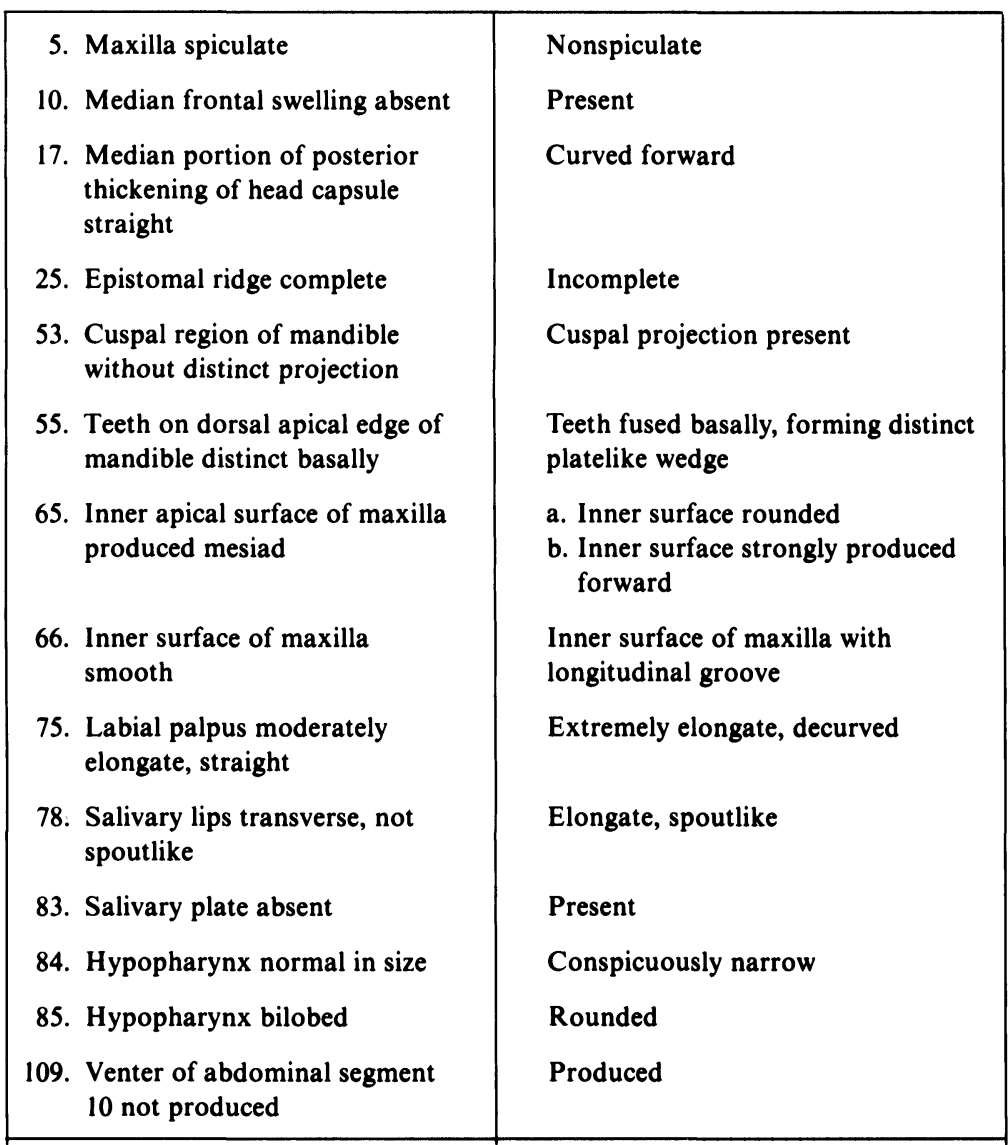

The sister-group relationship of Ptiloglossa and Crawfordapis is strongly supported by the presence of a longitudinal groove on the inner maxillary surface (character 66). Weaker support for this relationship is indicated by character 109 , the projection of the venter of abdominal segment 10 (this projection is conspicuous in some specimens of Crawfordapis but is only weakly developed in one specimen from Panama). 


\section{Adult Characters}

In a study of adult diphaglossines, Michener (1966) discussed the similarities of Crawfordapis to Ptiloglossa and Caupolicana. Four characters found in Crawfordapis were said to be more or less Caupolicana-like: (4) outer hind tibial spur of male normal, articulated at base like inner spur; (6) lateral extremities of terga of male without areas of short, dense, erect hair; (7) sixth tergum of male with posterior margin not thickened or sulcate; (9) eighth sternum of male with apical process rather heavily pigmented, not downcurved. The similarity based on character 4 is definitely symplesiomorphic as the fusion of the hind tibial spur and the tibia is found only in Ptiloglossa. The other three characters appear to be plesiomorphic as well in that they represent the absence of some rather unusual features.

Similarities between adult Crawfordapis and Ptiloglossa appear to be apomorphic for diphaglossines: (1) clypeus strongly elevated above level of adjacent parts of face; (2) marginal cell prolonged basally as a narrow sinus to apex of stigma; (3) expanded second and third hind tarsal segments of female considerably expanded above. This evidence also supports the Crawfordapis-Ptiloglossa sister-group relationship indicated by larval characters, but must be considered tentative until a comprehensive cladistic analysis of adult colletids has been performed.

\section{SUMMARY}

Crawfordapis luctuosa, a large colletid bee, was studied at two nest aggregations in the mountains of Costa Rica. The aggregations were in exposed sites formed by landslides or clearing. Female bees slowly abandoned the aggregations as they became overgrown with vegetation. Several nests are described. In contrast to the crepuscular habits of the closely related genus Ptiloglossa, Crawfordapis was active primarily between 0930 and $1400 \mathrm{hrs}$. Some individually marked females showed a high degree of constancy in nest visitation, while others visited several nests in succession. The exact explanation of this behavior is not yet known. The previously unknown larvae of Crawfordapis luctuosa are described. Information from these larvae supports the placement of the genus in the 
tribe Caupolicanini that was suggested from the systematic study of adults, and indicates that Crawfordapis may be the sister-group of Ptiloglossa.

\section{ACKNOWLEDGMENTS}

We wish to thank C. D. Michener and J. G. Rozen, Jr., for making helpful suggestions on the manuscript and R. W. Brooks for the loan of Crawfordapis larvae from Panama. The Tropical Science Center, San Jose, Costa Rica provided permission to study Crawfordapis within the Monteverde Cloud Forest Reserve. The Organization for Tropical Studies provided logistical support for a portion of the field work. Thanks are due also to the community of Monteverde for its friendly support of biologists and appreciation of their work.

\section{Literature Cited}

Brockmann, H. J. and R. Dawkins.

1979 Joint nesting in a digger wasp as an evolutionary stable preadaptation to social life. Behavior 71:203-245.

Brockmann, H. J., A. Grafen, and R. Dawkins.

1979 Evolutionarily stable nesting strategy in a digger wasp. J. Theor. Biol. 77:473-496.

EICKWORT, G. C.

1975 Gregarious nesting of the mason bee Hoplitis anthocopoides and the evolution of parasitism and sociality among megachilid bees. Evolution 29:142-150.

EICKWORT, G. C.

1981 Presocial Insects in Social Insects, Vol. II, ed. Henry Hermann, Academic Press, NY, pp. 199-280.

Eickwort, G. C., K. R. Eickwort, AND E. G. Linsley.

1977 Observations on nest aggregations of the bees Diadasia olivacea and $D$. diminuta (Hymenoptera: Anthophoridae). J. Kansas. Ent. Soc. 50:1-17.

LaWton, R. AND V. Dryer.

1980 The vegetation of the Monteverde Cloud Forest Reserve. Brenesia 18:101-116.

MCGinLEY, R. J.

1981 Systematics of the Colletidae based on mature larvae with phenetic analysis of apoid larvae (Hymenoptera: Apoidea). Univ. Calif. Pub. Ent. 91:1-307. 
Michener, C. D.

1966 The classification of the Diphaglossinae and North American species of the genus Caupolicana (Hymenoptera, Colletidae). Univ. Kansas Sci. Bull. 46:717-751.

MiCHener, C. D.

1974 The Social Behavior of the Bees. Harvard University Press, Cambridge, Massachusetts.

ROBERTS, R. B.

1971 Biology of the crepuscular bee Ptiloglossa guinnae $n$. sp. with notes on associated bees, mites and yeasts. J. Kansas Ent. Soc. 44:283-294. 

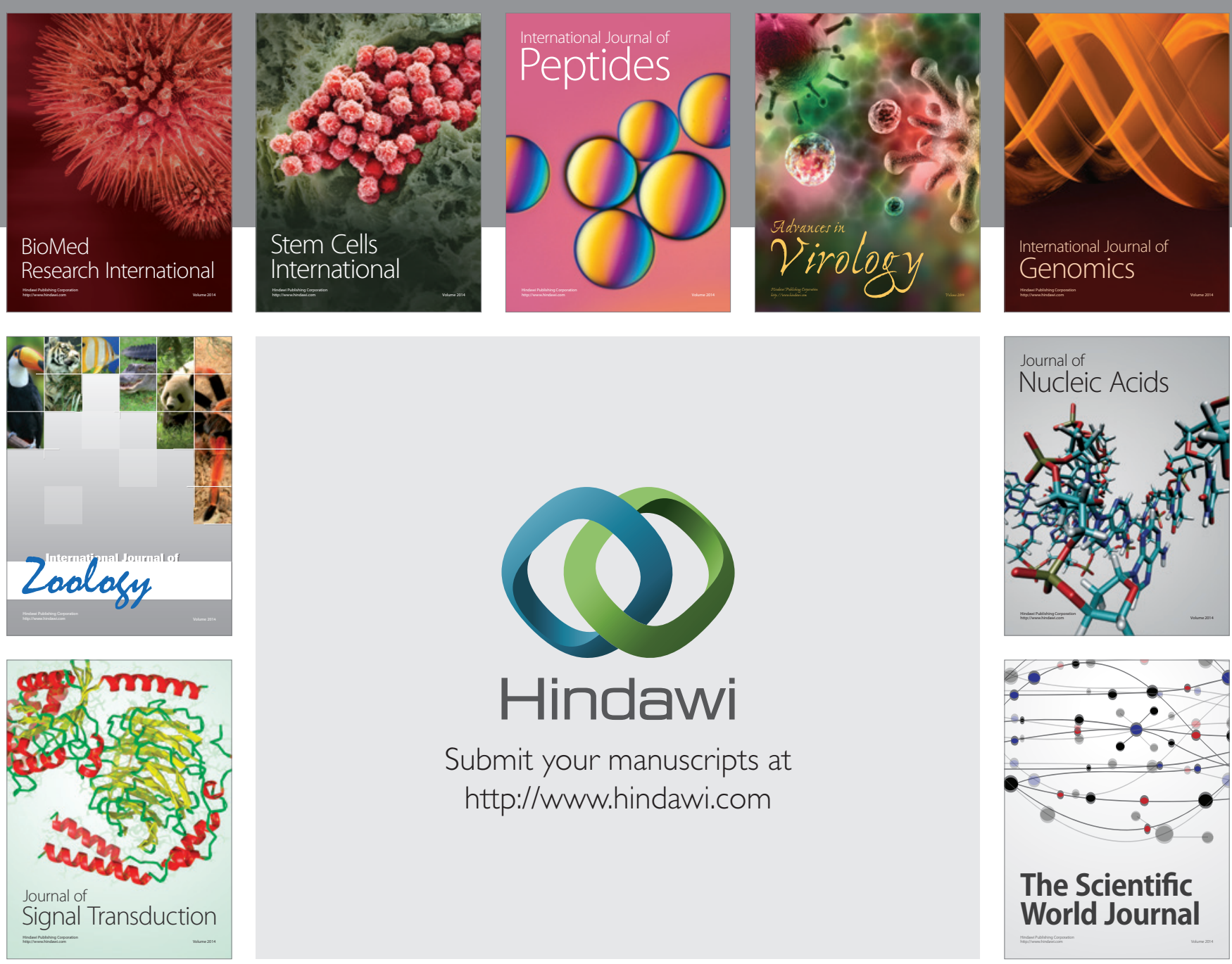

Submit your manuscripts at

http://www.hindawi.com
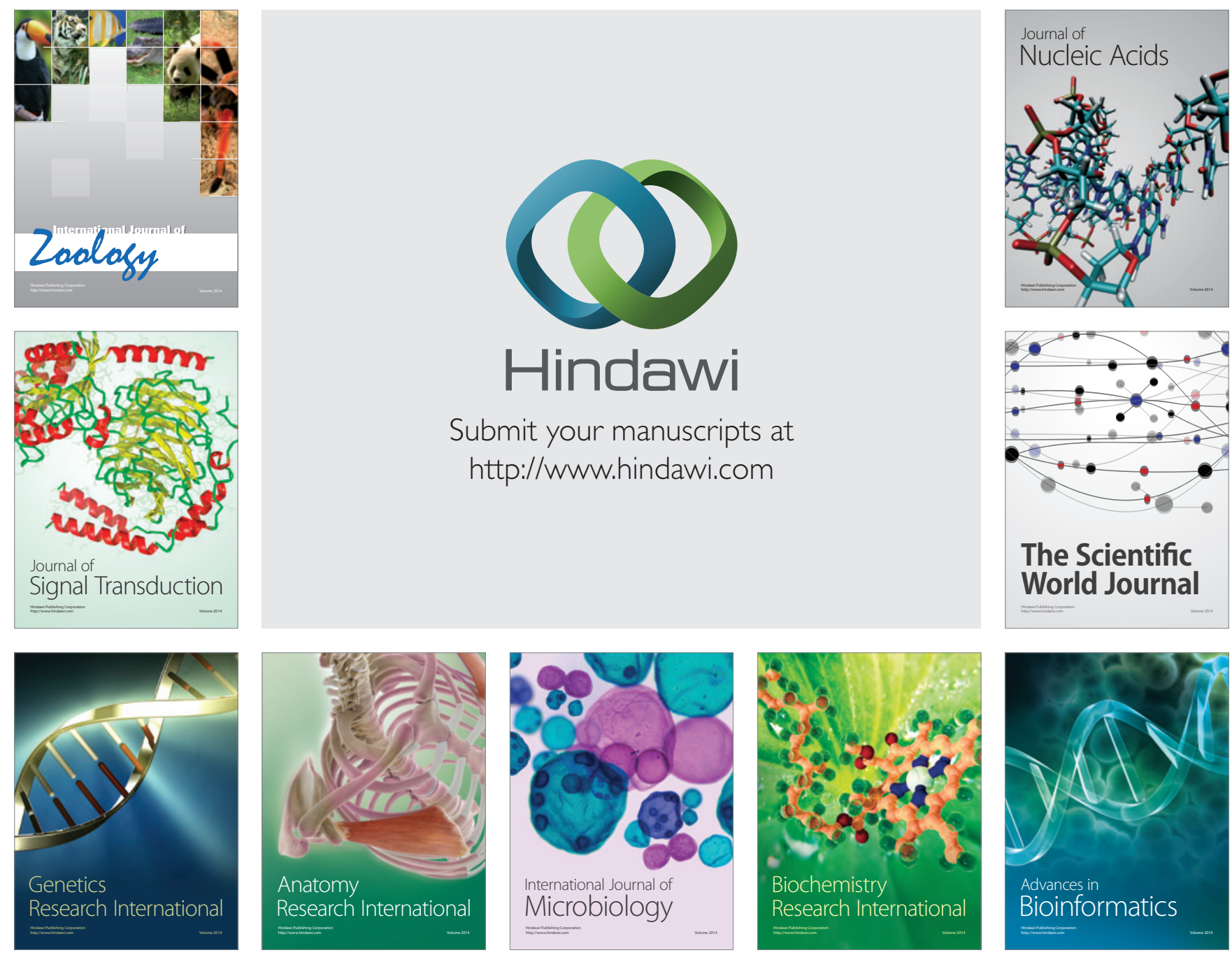

The Scientific World Journal
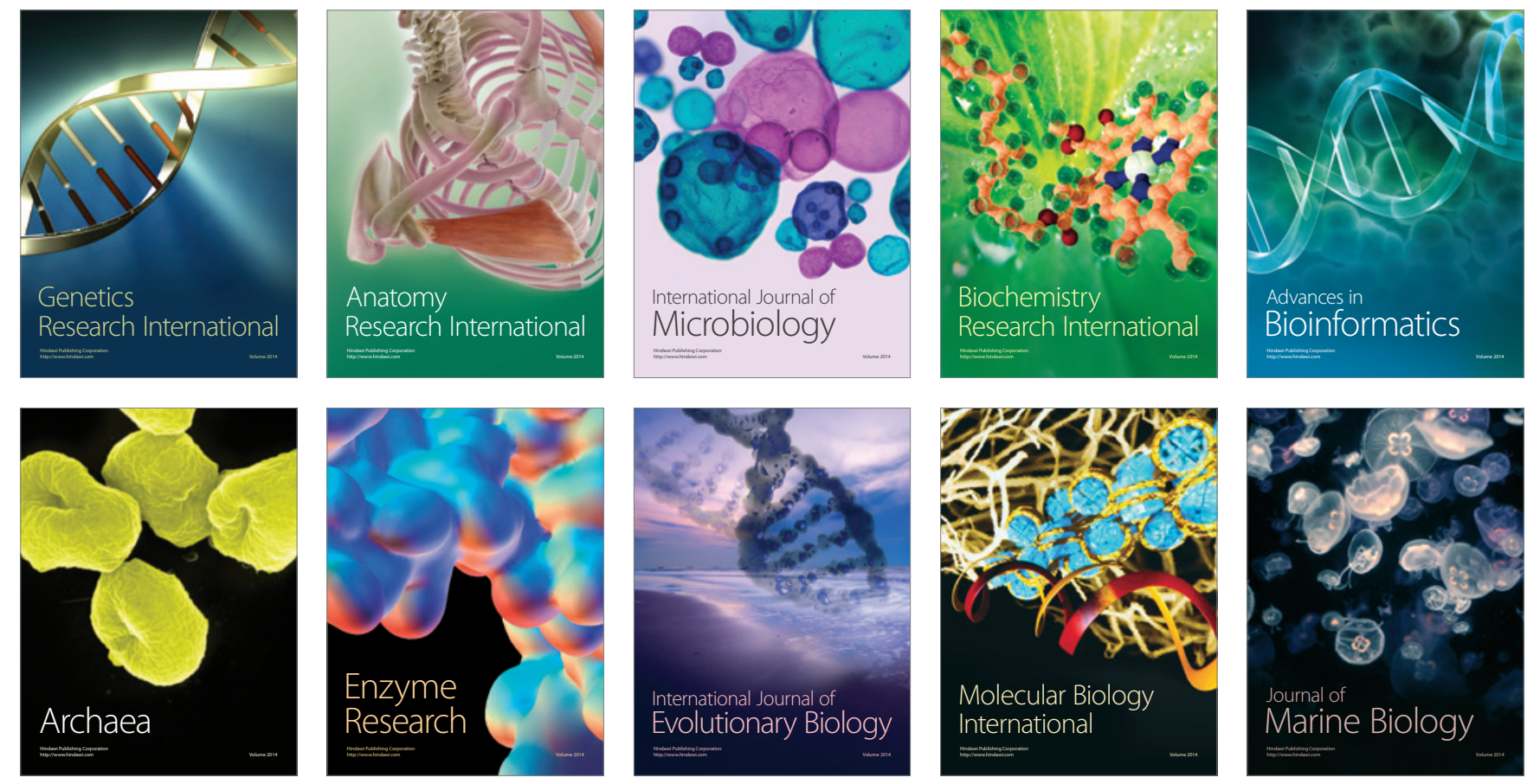